\title{
Eavesdropping on the user experience

\author{
Learning how students perceive the library through Yik Yak
}

$\mathbf{S}$

ocial media is increasingly an outlet for customers to discuss their service experiences. A 2014 survey by VentureBeat Insight found that we complain 879 million times a year on social networking sites. ${ }^{1}$ Companies such as Dell, Verizon, and Comcast have dedicated service personnel on platforms such as Twitter in order to make sure these complaints are not going unanswered and consequently diminishing the brand's reputation. ${ }^{2}$

Yet a recent survey showed that only 16\% of librarians view social networking sites (SNS) as having an "extremely important" customer service function as a tool to solicit complaints, suggestions, inquiries, and feedback. The overall knowledge gathering via this method has also been described as "underused and underexplored" among libraries. ${ }^{3}$ As Lydelle Gunton and Kate Davis noted, "Outside of libraries, there is a general awareness of the need to listen in to chatter in social media spaces in order to monitor brand and reputation, and importantly, to respond to customers and engage in dialogue with them. In this way, [social media] becomes a channel for service recovery, through which organisations can proactively address the concerns of customers." ${ }^{4}$

On the Murray State University (MSU) campus, a social media application called Yik Yak gained popularity among students in 2015. Curiosity led a few librarians to download the app, and we were surprised to discover that our libraries were fre- quently a topic of discussion. Users posed questions about our hours or services or complained about the facilities or resources. Monitoring the feed has enabled us to surreptitiously eavesdrop on the user experience and to potentially use what we learn to improve our services.

\section{What is Yik Yak?}

Yik Yak is a free mobile app that essentially creates a "local bulletin board" where users can pose questions, make jokes, brag about their exploits, or get support from a virtual community that is defined by the geographic location of your mobile phone. ${ }^{5}$ It is available for both iOS and Android devices. Posts are referred to as yaks, and users can upvote yaks they like or exchange replies with the original poster. Geofencing restricts the conversation to a "herd" of users within a 1.5- to 10-mile radius. Yaks that are deemed offensive, unimportant, or negative can be removed from the feed permanently with downvotes from five users

When it launched in 2013, the app touted the anonymity it offered users. But like JuicyCampus in the late 2000s, this

Elizabeth Price is business librarian and assistant professor at James Madison University, email: price2el@jmu.edu, and Rebecca Richardson is research and instruction librarian and assistant professor at Murray State University, email: rrichardson5@ murraystate.edu

C 2017 Elizabeth Price and Rebecca Richardson 
feature opened the door for cyberbullying and cruelty. In response, Yik Yak focused its target audience to users 18 and older and disabled the app on school campuses below the college level. ${ }^{6}$ Yik Yak further tries to restrict gossip by banning posts that contain personally identifiable information such as names, phone numbers, or social media profiles and prompting users to think carefully about whether a "yak is cool to post" if it contains threatening or abusive language. In addition to selfpolicing through community downvoting, users can flag posts as abusive, offensive, or sexually explicit and ban users who are repeat offenders.

By January 2016, Yik Yak had spread to more than 2,000 college campuses in the United States. This happened even as 72 women's and civil rights groups have pressured the federal government to protect students from online harassment through Yik Yak and similar products. ${ }^{7}$ Recently integrated Yik Yak features have reduced the strict anonymity that had been the app's trademark, enabling users to post under self-selected handles and to enter private chats with others. However, posting or replying entirely anonymously is still an option for those who prefer it.

\section{What we learned}

We began systematically capturing any mention of Waterfield (our main library), Pogue (MSU's special collections library), or the word library, on the local Yik Yak feed during a six-month period from November 1, 2015, through May 15, 2016. There is no way to archive yak transcripts as text, so screenshots were captured on iPhones and then typed into an Excel spreadsheet. It is impossible to say whether this was every library yak during the time period because yaks could have been downvoted or fallen off the main feed in between the times we checked the app each day (morning, afternoon, evening, and night). In total, we collected 51 questions about library services asked on Yik
Yak, and 67 posts that provided feedback about students' library experience (either compliment or complaint).

Three librarians then coded each yak in the feedback category as being positive, negative, or neutral. Overwhelmingly, the comments that were posted were viewed as negative (85\%). The complaints mostly confirmed problems that we already had identified and were related to our main building, which was a student center before being converted to a library in the late 1970s. Students voiced their frustrations about classmates who did not respect noise zones (15\%), the lack of computers, tables, and electrical outlets (14\%), fluctuations in the building temperature (13\%), the state of the library bathrooms (5\%), and even how the library smelled (4\%). The most frequently asked questions were about Waterfield Library hours (16\%) and how they could use the copiers, printers, and scanners in our main computer lab (9\%).

Takeaways that can be parsed from the yaks include:

- Daily hours were not immediately identifiable to users on the library website. The hours also were not properly displaying when searched in Google during the spring 2016 semester, a situation we have since fixed.

- Signage could be improved for the location of the bathrooms and the copy machines. The copy machines might benefit from directions similar to those currently on the scanners as Generation Z students become less familiar with this technology.

- More computers would be beneficial, and we might want to explore policies about the type of computer usage permitted during peak times in the semester. Another alternative might be creating additional stand-up, 15-minute work stations to allow students to print quickly when they are short on time.

- Students like the different noise zones and are fierce about enforcing the quiet areas, but perhaps they could use a little more help from staff in this ongoing 
battle. More computers in areas that are considered quiet zones would be welcome.

- The appropriateness of napping in public is a surprisingly divisive issue among students. Perhaps we should follow the lead of other libraries and install nap

Our library really needs to more
tables and chairs.
pods. ${ }^{8}$

In all, these topics might be worth discussing as part of the user experience and institutional planning priorities. We know that we have too few seats, study rooms, and even computers. The electrical limitations of our current building severely constrain our efforts to increase the number of outlets, although

Can we get a "cry room" installed
into the library. I think it would be
really helpful for this time of the
semester.

library or simply to show how essential the library is for our students? Perhaps, particularly if combined with more traditional data gathered through surveys or focus groups. Unfortunately, Yik Yak's anonymity means we cannot tell how many of our users are complaining, or whether it is the same person griping over and over, or even whether library staff members are the source of the complaints (after all, there would be no way to prove it wasn't us).

\section{Conclusion}

Although some librarians might fear that students will view collecting information shared we had already attempted to remedy this during a remodeling project in summer 2014 that added chairs with outlets and USB sites. The bathrooms on all three floors of the library were remodeled in fall 2015 .

Overall, the complaints show that we have an aging building that does not meet all of the needs of modern students. A capital project to build a new main library at MSU has been tabled in favor of renovating and

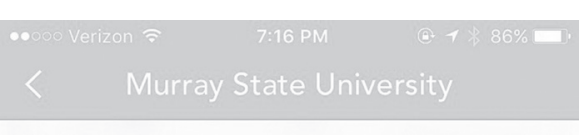
Murray Anybody know for sure if library is open today?? on social media as an intrusion into their private space, Ana Isabel Canhoto and Moira Clark found that concern may no longer be valid. "Customers have gone beyond accepting that firms eavesdrop on social media conversations. Instead, they expect companies to interact with them and to offer support across an array of platforms, even those not traditionally thought of as a business channel, for example Facebook." ${ }^{\circ}$ expanding the existing building. Even this project has no concrete timeline because of state and university budget issues. Could data collected from Yik Yak be used to persuade administrators to prioritize a new
Indeed, some users view complaining on social media as a way to influence outcomes. ${ }^{10}$ If we are not listening, how will students know we are responsive to their needs? 
Libraries need to be more proactive about documenting what their users are saying on social media and put that information to use in making strategic decisions about library services. This likely will require staying abreast of the conversations happening on both established sites like Facebook and Twitter and identifying the possibilities of emerging apps like Yik Yak or whatever emerges next. Steven Bell put it best when discussing his library patrons' tweets, "Their [posts] can provide valuable intelligence in improving what we do and how we do it. It can help us repair what is broken or build something new and better. . . . Why wouldn't we want to use it to provide a better library experience?"11

\section{Notes}

1. John Koetsier, "Social Media: We Complain 879 Million Times/Year (and Facebook is our Top Target," VentureBeat Insight (December 12, 2014), http://venturebeat.com/2014/12/12/social-mediawe-complain-879-million-timesyear-andfacebook-is-our-top-target/ (accessed August 3, 2016).

2. Liye Ma, Baohong Sun, Sunder Kekre, "The Squeaky Wheel Gets the Grease-An Empirical Analysis of Customer Voice and Firm Intervention on Twitter," Marketing Science 34, no. 5 (2015): 627-645.

3. TBI Communications, Use of Social Media by the Library: Current Practices and Future Opportunities (London: Taylor \& Francis Group, 2014); Dora Yu-Ting Chen, Samuel Kai-Wah Chu, and Shu-Qin Xu, "How Do Libraries Use Social Networking Sites to Interact with Users," Proceedings of the American Society for Information Science and Technology 49, no. 1 (2012): 1-10.

4. Lyndelle Gunton and Kate Davis, "Beyond Broadcasting: Customer Service, Community and Information Experience in the Twittersphere," Reference Services Review 40, no. 2 (2012): 224-227.

5. Jonathan Mahler, "Who Spewed That Abuse? Anonymous Yik Yak App Isn't Telling," The New York Times (March 8, 2015), http://www.nytimes.com/2015/03/09/ technology/popular-yik-yak-app-confersanonymity-and-delivers-abuse.html (accessed August 2, 2016).

6. "Safety Center," Yik Yak (2016), http://safety.yikyak.com/ (accessed August 3, 2016).

7. Peter Schmidt, "Women's Groups Urge Colleges and Government to Rein In Yik Yak," Chronicle of Higher Education (October 21, 2015), http://chronicle.com/article/ Women-s-Groups-Urge-Colleges/233864 (accessed August 3, 2016).

8. Olivia B. Waxman, "Napping Around: Colleges Provide Campus Snooze Rooms," Time (August 29, 2014), http://time. com/3211964/nap-rooms-at-universities/ (accessed August 3, 2016).

9. Ana Isabel Canhoto and Moira Clark, "Customer Service 140 Characters at a Time: The Users' Perspective," Journal of Marketing Management 29, no. 5-6 (2013): 522-544.

10. Jan H. Kietzmann, Kristopher Hermkens, Ian P. McCarthy, and Bruno S. Silvestre, "Social Media? Get Serious! Understanding the Functional Building Blocks of Social Media," Business Horizons 54 (2011): 241-251.

11. Steven Bell, "Students Tweet the Darndest Things About Your Library-And Why You Need to Listen," Reference Services Review 40 (2012) no. 2: 217-220. n

\section{Upcoming ACRL e-Learning}

ACRL is offering a variety of online courses and webcasts this winter. Upcoming topics include:

Modern Pathfinders: Easy Techniques to Make Better Research Guides (Webcast: February 2017)

Charting a New Course for Credit-Bearing Information Literacy Courses in Higher Education (Webcast: February 22, 2017) 